\section{Persistent B Lymphocyte Depletion After an Ultralow Dose of Rituximab for Pemphigus Vulgaris}

\author{
Lazzarotto A, Ferranti M, Meneguzzo A, Sacco G, Alaibac M \\ Dermatology Unit, University of Padua, Padua, Italy
}

J Investig Allergol Clin Immunol 2018; Vol. 28(5): 347-348

doi: $10.18176 /$ jiaci.0283

Key words: Rituximab. Pemphigus. Autoimmunity. Skin. B cells.

Palabras clave: Rituximab. Pénfigo. Autoinmunidad. Piel. Células B.

Pemphigus vulgaris is an autoimmune bullous disease affecting the skin and mucosa. It is caused by autoantibodies targeting the adhesion molecules desmoglein 1 and desmoglein 3, which, respectively, mediate adhesion between keratinocytes in skin and mucosa, resulting in the formation of blisters and erosions. Early recognition and treatment are crucial for remission of this disorder. Treatment for severe pemphigus traditionally includes long-term corticosteroids and immunosuppressants [1]. Rituximab, a chimeric monoclonal antibody against the CD20 antigen of B lymphocytes, was recently introduced and has proven to be effective in resistant and life-threatening pemphigus [2]. Protocols for administration of rituximab are determined for use in nonHodgkin lymphoma $\left(375 \mathrm{mg} / \mathrm{m}^{2}\right.$ once a week, with duration depending on the type of lymphoma) and for rheumatoid arthritis ( 2 doses of $1000 \mathrm{mg}$ given 2 weeks apart) [3]. A lower dose of rituximab (500 $\mathrm{mg}$ at 2 weeks interval) can be used in pemphigus [4-6].

A 67-year-old woman was referred to our dermatology department for recent onset of erosive lesions of the oral cavity. The patient complained of severe difficulty swallowing, forcing her to feed almost exclusively with a liquid diet. The skin was not involved, showing only signs of previously active lesions. She denied trauma and application of topical drugs on the areas involved. Her medical history did not reveal any association with other immune-mediated diseases. Evaluation of circulating anti-DSG1, anti-DSG3, and antiBP180 antibodies revealed a high anti-DSG3 autoantibody titer (192.13 U/mL, normal value $<7 \mathrm{U} / \mathrm{mL}$ ), which is consistent with a diagnosis of pemphigus vulgaris. Treatment was initially started with intravenous methylprednisolone $80 \mathrm{mg} / \mathrm{d}$ for 2 weeks, which was thereafter slowly tapered to $40 \mathrm{mg} / \mathrm{d}$ over 2 weeks, with complete remission. The patient was then treated with oral prednisone $50 \mathrm{mg} / \mathrm{d}$ for 1 month and $25 \mathrm{mg} / \mathrm{d}$ for a further month. At this time, the disease relapsed, with oral involvement only, and azathioprine $100 \mathrm{mg} / \mathrm{d}$ was combined with prednisone $25 \mathrm{mg} / \mathrm{d}$ for 3 months. The oral lesions did not resolve. Consequently, we decided to administer rituximab [7] in a 2-dose regimen ( 2 weeks apart) of $500 \mathrm{mg}$ per dose. Prior to infusion of rituximab, the patient was premedicated with intravenous acetaminophen $1000 \mathrm{mg}$, chlorphenamine $10 \mathrm{mg}$, and methylprednisolone $20 \mathrm{mg}$ diluted in $100 \mathrm{~mL}$ of normal saline. Rituximab $500 \mathrm{mg}$ was then diluted in $500 \mathrm{~mL}$ of normal saline and infused at $50 \mathrm{~mL} / \mathrm{h}$ for the first 30 minutes and then at incremental rates of $50 \mathrm{~mL} / \mathrm{h}$ every 30 minutes, up to $400 \mathrm{~mL} / \mathrm{h}$. However, after 120 minutes, the patient began to complain of chest tightness, the infusion had to be interrupted, and the dose of rituximab was reduced to about $250 \mathrm{mg}$. Seven days after the administration of $250 \mathrm{mg}$ of rituximab CD19, the B-lymphocyte percentage (pre-B and mature B lymphocytes) was $0 \%$. During the following months, the patient improved, with almost complete remission, and is now receiving low-dose maintenance corticosteroid therapy. Blood tests at 3 months and 6 months after the infusion of $250 \mathrm{mg}$ of rituximab showed a stable $0 \%$ rate for $\mathrm{CD} 19^{+} \mathrm{B}$ lymphocytes.

The optimal dosage of rituximab for treatment of pemphigus has not been clearly defined. The initially used regimen was that of the lymphoma protocol $\left(375 \mathrm{mg} / \mathrm{m}^{2}\right)$ for 4 weeks; thereafter, the protocol used in patients with rheumatoid arthritis (2 infusions of $1000 \mathrm{mg}$ given 2 weeks apart) or a low-dose regimen (500 $\mathrm{mg}$ at a 2 -week interval) was preferred because of its better safety profile [8]. The clinical improvement and the persistently suppressed CD19 B-lymphocyte count over 6 months of follow-up suggest the potential efficacy of this reduced-dose protocol (single 250-mg dose), which was arrived at purely by chance.

Further studies, especially longitudinal and controlled studies, are needed to confirm both short- and long-term efficacy and the possible better safety profile of this regimen, compared with usual protocols for administration of rituximab in patients with pemphigus vulgaris, especially severe forms resistant to traditional immunosuppressants [9]. In this regard, a recent study [10] demonstrated how a single, minimal dose of rituximab $\left(1 \mathrm{mg} / \mathrm{m}^{2}\right)$ effectively depleted CD $20^{+}$cells in healthy volunteers, suggesting that ultralow rituximab regimens could be a plausible approach for the treatment of autoimmune skin conditions.

\section{Funding}

The authors declare that no funding was received for the present study.

\section{Conflicts of Interest}

The authors declare that they have no conflicts of interest.

\section{References}

1. Pollmann R, Schmidt T, Eming R, Hertl M. Pemphigus: a Comprehensive Review on Pathogenesis, Clinical Presentation and Novel Therapeutic Approaches. Clin Rev Allergy Immunol. 2018;54:1-25.

2. Hebert $V$, Joly $P$. Rituximab in pemphigus. Immunotherapy. 2018; 10:27-37.

3. Murrell D, Sprecher E. Rituximab and short-course prednisone as the new gold standard for new-onset pemphigus vulgaris and pemphigus foliaceus. Br J Dermatol. 2017;177:1143-4.

4. Chadha A, Khopkar U, Nitya M, Lahori V. Follow-up data of rituximab as adjuvant therapy in pemphigus. Indian J Dermatol. 2017;62:671-3.

5. Gupta J, Raval R, Shah A, Solanki R, Patel D, Shah K, et al. 
Low-dose rituximab as an adjuvant therapy in pemphigus. Indian J Dermatol Venereol Leprol. 2017;83:317-25.

6. Hertl M, Jedlickova H, Karpati S, Marinovic B, Uzun S, Yayli S, et al. Pemphigus. S2 Guideline for diagnosis and treatment - guided by the European Dermatology Forum (EDF) in cooperation with the European Academy of Dermatology and Venereology (EADV). I Eur Acad Dermatol Venereol. 2014;29:405-14.

7. Sanchez J, Ingen-Housz-Oro S, Chosidow O, Antonicelli F, Bernard P. Rituximab as Single Long-term Maintenance Therapy in Patients With Difficult-to-Treat Pemphigus. JAMA Dermatology. 2018;154:363-5.

8. Wang H, Liu C, Li Y, Huang Y. Efficacy of Rituximab for Pemphigus: A Systematic Review and Meta-analysis of Different Regimens. Acta Dermatol Venereol. 2015;95:92832.

9. Kanwar A, Vinay K, Sawatkar G, Dogra S, Minz R, Shear N, et al. Clinical and immunological outcomes of high- and low-dose rituximab treatments in patients with pemphigus: a randomized, comparative, observer-blinded study. $\mathrm{Br} J$ Dermatol. 2014;170:1341-9.

10. Schoergenhofer C, Schwameis M, Firbas C, Bartko J, Derhaschnig U, Mader RM, et al. Single, very low rituximab doses in healthy volunteers - a pilot and a randomized trial: implications for dosing and biosimilarity testing. Scient Rep. 2018;8:124-5.

1 Manuscript received March1, 2018; accepted for publication June 12, 2018.

Mauro Alaibac

Unit of Dermatology

University of Padua

Via Gallucci 4

35128 Padova, Italy

E-mail: mauro.alaibac@unipd.it 